\title{
AS AÇÕES POSSESSÓRIAS E OS CAPÍTULOS DA SENTENÇA
}

\author{
ODETE BATISTA DIAS ALMEIDA
}

Revista Esmat, Palmas, Ano 2, n² 2, pag. 151 a 165 - jan/dez $2010^{2}$ 


\title{
AS AÇÕES POSSESSÓRIAS E OS CAPÍTULOS DA
} SENTENÇA

\author{
Odete Batista Dias Almeida
}

\begin{abstract}
RESUMO
Integrando o núcleo dos procedimentos especiais, o tema em evidência contempla várias particularidades expressas na legislação nacional. Por sua natureza, destaca-se pelo modo de condução do processo, observados os critérios legalmente permitidos referentes a cada ação em específico. No caso de discussão da posse, verifica-se a possibilidade de fungibilidade das ações, além da cumulação de pedidos, o que pode interferir nos comandos finais decisórios, os quais poderão ser executivos, mandamentais e condenatórios. Neste contexto, vale enfatizar os chamados "Capítulos da Sentença" - Teoria que remonta de Chiovenda-de relevância, em especial, em grau de recurso. Ainda, vale ressaltar a característica de duplicidade destas ações, cujo instituto se assemelha a outras técnicas de resposta, a exemplo do pedido contraposto e reconvenção, respeitando-se as especificidades que encerra. Referida explanação é o objetivo do presente trabalho.
\end{abstract}

\section{Palavras-chave:}

Posse. Fungibilidade. Duplicidade. Capítulos da Sentença.

\begin{abstract}
In integrating the core of the special procedures, the theme in evidence contemplates various particularities expressed in the national legislation.
\end{abstract}

\footnotetext{
'Juiza Substituta Auxiliar lotada na 1'a . Vara Cível da Comarca de Gurupi/TO. Pós-Graduada em Direito Processual Civil (1997) e Direito Comercial (1999) pela Universidade Federal de Uberlândia. Exerceu a docência como titular da cadeira de Processo Civil e Prática Jurídica na Faculdade Objetivo até o mês de novembro/2009 (Rio Verde/GO). Lecionou Direito Processual Civil e Direito Civil na Faculdade Almeida Rodrigues (Rio Verde/GO). Ministrou aulas de Processo Civil no Instituto $\mathrm{n}^{\circ} .1$ (Preparatório Para Concursos Públicos - Rio Verde/GO). Ministrou Cursos de Atualização Jurídica (Direito Constitucional - Controle de Constitucionalidade) para professores universitários e acadêmicos de direito em Rio Verde-GO. Ministrou curso preparatório para o exame da OAB. Colaboradora da Revista "OAB in Foco"Seccional de Uberlândia-MG -, para a qual escreveu 03 (três) artigos científicos nas Revistas de $\mathrm{n}^{\circ}$ s. 20, 15 e 12, intitulados, respectivamente: "Ativismo Judicial: Uma Moderna Tendência no STF"; "Controle Abstrativizado da Declaração de Inconstitucionalidade do $\S 1^{\circ}$. do Artigo $2^{\circ}$. da Lei de Crimes Hediondos" e "Improbidade Administrativa e o STF". Email: odetealmeida@tjto.jus.br
} 
For its nature, it is highlighted by its operational procedures, observing the legally permitted criteria related to each action specifically. In this context, it is worth to emphasize the so called "Chapters of Sentencing"- a theory that refers to Chiovenda's - as relevant, specially in regards to degree of recourse. In the discussion of the right to possession, there is the possibility of mix actions, as well as, cumulation of requests that can interferer with the sentencing that in its turn can be an executive order, a mandate, or a conviction. More so, it is worth to point out the duplicity of these actions, whose precept is similar to other techniques of response, as an example of de requested counterpoint and countersuit, respecting the particularities within it. The referred explanation is the objective of this present work.

Key-words:

Possession. Mix Actions. Duplicity. Chapters of Sentencing.

\section{INTRODUÇÃO}

Inseridas no contexto dos procedimentos especiais, as Ações Possessórias estão previstas nos artigos 920/933 do Código de Processo Civil Brasileiro, trazendo à baila diversas nuanças que merecem destaque. Nesta linha, ressalte-se que em matéria de possessórias a legislação pátria prevê algumas peculiaridades procedimentais, a exemplo da possibilidade de fungibilidade das ações específicas de que tratam, além da cumulação de pedidos que poderá culminar na bipartição (ou tripartição, quiçá) dos comandos decisórios respectivos.

Não é demais enfatizar que, dentro do direito material, a discussão sobre o conceito da posse encontrou diversos paradigmas que remontam a Savigny e Ihering, buscando ainda os seus contornos na doutrina alemã, inclusive (doutrina de Astolfo Rezende). ${ }^{2}$

Outrossim, é certo que o presente trabalho limitar-se-á na descrição da forma procedimental afeta às ações possessórias, restando a narrativa de sua natureza jurídica (pautada nas Teorias dos ilustres juristas acima identificados) reservada aos civilistas que da matéria se valem.

${ }^{2}$ REZENDE, Astolfo, Manual de Código Civil (Paulo Lacerda), Ed. Jacinto Ribeiro, 1918, vol. VII, p. 4 apud Guido Arzua, Posse, o Direito e o Processo, 2 $2^{a}$. Ed., Revista dos Tribunais, 1978, $\mathrm{n}^{\circ}$. I, p.14. 
Deste modo e não cuidando este escrito do direito material alusivo à posse, mas sim, do direito processual e em prosseguimento, mister se faz alinhar as modalidades das Ações Possessórias vigentes no ordenamento jurídico, destacando-se as seguintes medidas legais, a saber:

a) Ação de Manutenção de Posse, consubstanciada na turbação (artigo 926 CPC);

b)Ação de Reintegração de Posse, por sua vez pautada no esbulho possessório (artigo 926 CPC) e, por fim,

c) Ação de Interdito Proibitório, amparada pela ameaça (artigo 932 CPC).

É certo que a Ação de Nunciação de Obra Nova (artigos 934 a 940 do CPC) e os Embargos de Terceiro (artigos 1.040 a 1.054 do CPC) são institutos jurídicos que podem ser manejados na defesa da posse, porém, não se limitam exclusivamente à tutela possessória, $\mathrm{o}$ que merece ressalva, neste particular.

Assim e como regra geral, o sistema processual vigente se vale das clássicas ações possessórias alhures declinadas, quais sejam: Manutenção, Reintegração e Interdito Proibitório, sendo as particularidades das referidas ações o objeto da análise em comento.

Neste intróito, ainda há que se mencionar a necessária diferenciação entre o juízo possessório (jus possessionis - sendo este o processo puro, onde só se discute a posse, qual seja: o direito à proteção possessória) e o juízo petitório (jus possidendi - onde o processo se forma para a discussão do domínio, qual seja: o direito de possuir).

$\mathrm{Na}$ linha acima e em se tratando de possessórias, é patente a vedação da discussão do domínio, o qual encontra óbice expresso no artigo 923 do Código de Processo Civil Brasileiro, ${ }^{3}$ donde se extrai que, pendente ação possessória, há franco impedimento para a ação petitória.

\footnotetext{
${ }^{3}$ Art. 923 - Na pendência de processo possessório, é defeso, assim ao autor como ao réu, intentar a ação de reconhecimento do domínio.
} 


\section{No dizer do doutrinador Luiz Guilherme Marinoni: ${ }^{4}$}

O juizo da ação possessória, para realmente viabilizaro alcance da tutela possessória, não pode se permitir discussões inerentes ao domínio, sob pena de a tutela jurisdicional, que deveria ser outorgada à posse, ser deferida sempre em favor do proprietário. Note-se que o possuidor esbulhado pelo titular do domínio sequer teria razão para propor a ação de reintegração de posse, já que o proprietário-demandado sempre receberia, em seu favor, a tutela jurisdicional. É a própria autonomia do conceito de posse diante da propriedade que exige a limitação na cognição.

Ressalte-se que o impedimento citado, para a maioria da doutrina, integra o chamado Pressuposto Processual Negativo, o qual deve ser observado pelo magistrado quando da análise do feito em específico.

Por fim, há que se mencionar que, uma vez alegado, o domínio não possui o condão de fazer coisa julgada, atuando no feito tãosomente como fundamento de resposta.

Esta é a lição do mestre Humberto Theodoro Júnior, ${ }^{5}$ a saber:

Discute-se, portanto, no "possessório" tão-somente o jus possessionis, que vem a ser a garantia de obter proteção juridica ao fato da posse contra atentados de terceiros praticados ex propria auctoritate. Exercitamse, pois, no juizo possessório, faculdades jurídicas oriundas da posse em si mesma.

No juizo "petitório", a pretensão deduzida no processo tem por supedâneo o direito de propriedade, ou seus desmembramentos, do qual decorre "o direito à posse do bem litigioso".

Os dois juizos são, como se vê, totalmente diversos, já que a causa petendi de um e de outro são até mesmo inconciliáveis. E, justamente por isso, não se pode cogitar de coisa julgada, ou litispendência, quando se

"MARINONI, Luiz Guilherme e ARENHART, Sérgio Cruz. Procedimentos especiais. São Paulo: Editora Revista dos Tribunais, 2008.p. 94.

${ }^{5}$ THEODORO JR., Humberto. Curso de Direito Processual Civil: procedimentos especiais. V. III. Rio de Janeiro: Editora Forense, 2008.p. 138 
coteja o julgamento e o processo possessórios com a sentença e o processo petitórios. "Grifamos.

\section{DO PRINCÍPIO DAFUNGIBILIDADE}

Insta salientar que, diferentemente de outras modalidades de ações, as possessórias permitem a fungibilidade entre si, sendo que referida circunstância é incapaz de redundar na inépcia da petição inicial, haja vista que poderá o autor equivocar-se no tocante à medida proposta que, nem por isso, deixará o magistrado de proceder ao recebimento da peça inicial, adequando-a, de ofício, à medida respectiva pertinente.

Como exemplo, cite-se a propositura da medida de manutenção de posse quando, na realidade, pela narrativa e provas carreadas aos autos, restou evidenciado que a parte sofrera esbulho possessório (e não turbação) hábil, portanto, ao manejo da ação de reintegração de posse. Nesta seara, é possível ao magistrado receber a peça inicial como sendo reintegratória, adequando o feito à pretensão corretamente tipificada no ordenamento.

A esta circunstância se amolda perfeitamente o chamado Principio da Fungibilidade das Possessórias, especificamente previsto no artigo 920 do Código de Processo Civil Brasileiro, ${ }^{6}$ lembrando que referida hipótese de fungibilidade, segundo a doutrina e jurisprudência pacíficas, pode ser manejada em qualquer instância, o que deve ser observado.

Sabe-se que o Princípio da Fungibilidade, de utilização mais frequente nos Tribunais pátrios em seara recursal, assim o é de forma cautelosa e reservada, de adequação sempre em caso de identificação da chamada "dúvida objetiva", a qual ressurge da impossibilidade de se apurar, de simples leitura do comando decisório, se o mesmo refere-se a uma decisão interlocutória ou a uma sentença, o que, por vezes, é passível de acontecer.

Entretanto e em sede singular (propositura da ação em primeiro grau de jurisdição), referido Princípio encontra óbice rotineiro, haja vista que à parte compete identificar, no feito, a adequação exata de

${ }^{6}$ Art. 920 - A propositura de uma ação possessória em vez de outra não obstará a que o juiz conheça do pedido e outorgue a proteção legal correspondente àquela, cujos requisitos estejam provados. 
sua pretensão (Teoria da Substanciação da lavra de Enrico Túllio Liebman - homenageada pelo Código de Processo Civil Brasileiro 7 no artigo 282, III, cuja redação imprime ao autor a obrigação de indicar os fatos e os fundamentos jurídicos do pedido).

Assim, o Princípio da Fungibilidade (expressamente previsto em seara das ações possessórias), é realmente uma peculiaridade afeta a este tipo de ação, merecendo destaque na forma identificada no ordenamento pela especificidade que encerra.

Apenas a título de comentário, é certo que, pela doutrina de Liebman, o "nome" da ação é irrelevante, posto que o direito de ação, em regra, não possui nome algum. Entretanto, os fatos e fundamentos jurídicos hão de estar evidenciados a fim de se atender ao regramento disposto no citado artigo.

\section{AÇÕES DÚPLICES}

Corroborando e também como outra particularidade, ressalte-se o disposto no artigo 922 do Código de Processo Civil Brasileiro, ${ }^{8}$ o qual prevê a possibilidade do requerido, numa ação possessória e em sua contestação, formular também a proteção da posse em seu favor, , cumulada com eventual pedido de indenização contra o autor.

Referida característica denomina-se de Ação Dúplice, em cuja hipótese o requerido tanto pode se defender quanto formular pedido outro em seu favor. Melhor explicando e em sentido material, significa que a defesa deste é o suficiente para dar ao mesmo o bem da vida em discussão no feito.

Como regra e salvo algumas exceções, sabe-se que nas modalidades de resposta (dentre estas incluindo a contestação), apenas se permite que o requerido faça um único pleito, qual seja: a improcedência do pedido inicial. Como exemplo e numa hipotética propositura de uma ação de cobrança, cujo comando sentencial declare que a mesma é indevida, em não havendo a propositura de

\footnotetext{
'DINAMARCO, Cândido Rangel. "Liebman e a cultura processual brasileira". In: Estudos em homenagem à Professora Ada Pellegrini Grinover. São Paulo: DPJ. 2005. Disponivel em http://www.abdpc.org.br/abdpc/imortal.asp?id=10

'Art. 922 - É lícito ao réu, na contestação, alegando que foi ofendido em sua posse, demandar a proteção possessória e a indenização pelos prejuizos resultantes da turbação ou do esbulho cometido pelo autor.
} 
reconvenção e acaso pretenda o requerido ver-se ressarcido de dano que entender sofrido, terá o mesmo que se valer de outra ação - desta vez indenizatória sua em desfavor do autor primitivo e em feito próprio.

Em se tratando de ações dúplices, no entanto, já na modalidade e no contexto da resposta poderá o requerido pleitear o pagamento de eventual indenização que entender devida em seu favor, além de pugnar pela improcedência do pedido do autor. Nesta seara, a exceção prevalece, sendo a ação possessória, quiçá, o exemplo mais marcante desta característica, ao lado, outrossim, das ações divisórias.

No dizer de Araken de Assis:

Do prisma material, é dúplice a ação, provocando o iudicium duplex, na qual a contestação do réu já basta à obtenção do bem da vida. Em geral, o autor pede e o réu somente impede; na actio duplex, o ato de impedir (contestação) já expressa um pedido contrário. Tal característica deriva do direito material posto em causa (rectius: mérito, pretensão processual ou objeto litigioso).

Em síntese, tem-se que a Ação Possessória é dúplice porque, em sentido processual, pode buscar o pagamento de eventual indenização e, em sentido material, pode também buscar a proteção possessória em favor do requerido.

Note-se que há sutil diferença entre a chamada ação dúplice, a reconvenção e o pedido contraposto, a qual vale destacar.

Como dito, na ação dúplice a situação dos litigantes é a mesma, não se podendo falar em autor e réu, pois ambos assumem, concomitantemente, a mesma posição. Ambos podem receber a tutela do bem da vida litigado, cujo pleito é referendado no corpo da peça contestatória.

A reconvenção, por sua vez, é uma modalidade de resposta cabível no rito ordinário na qual se permite que o réu não apenas ofereça resistência à pretensão buscada pelo autor, mas também pleiteie o reconhecimento de uma pretensão da qual se julga titular em face deste. Há uma ampliação do objeto da demanda, sendo a

9ASSIS. Araken. Procedimento Sumário. São Paulo. Editora Malheiros, 1996.p. 93 
mesma proposta em peça própria face ao feito principal, devendo ser ofertada no prazo da contestação. Relembre-se que somente é possível a propositura de reconvenção se não houver espaço para a argumentação na forma de ação dúplice.

Por fim, tem-se que o pedido contraposto é uma técnica de formulação de pedido, por parte do réu, na mesma oportunidade de oferecimento de sua defesa, sem a necessidade de utilizar-se do procedimento próprio da via reconvencional, cabível, entretanto, somente nos Juizados Especiais e no procedimento sumário.

Neste contexto, veja-se a doutrina de Juliana Demarchi: ${ }^{10}$

$O$ caráter dúplice de determinados pedidos de tutela decorrem de peculiaridades do direito material, no sentido de que a simples improcedência do pedido do autor confere provimento jurisdicional que assegura um bem da vida ao réu.

Reconvenção é modo de exercício do direito de ação, pelo réu, incidentalmente ao processo instaurado pelo autor.

O pedido contraposto é também uma forma de exercer o direito de ação, e se diferencia dos outros modos de se exercitar o direito de ação (reconvenção e propositura de demanda inaugural, por exemplo) pelos seus estreitos limites (imposições de ordem procedimental).

\section{DOS CAPÍTULOS DASENTENÇA}

Conforme dito alhures, as ações possessórias permitem a cumulação de pedidos, cuja previsão está expressa no artigo 921 do Código de Processo Civil Brasileiro ${ }^{11}$. Assim, permite-se cumular no mesmo feito os pedidos:

a) de proteção possessória, que receberá um comando decisório final de ordem executiva ou mandamental;

b) de indenização pelos prejuízos experimentados, que sofrerá um comando condenatório;

\footnotetext{
${ }^{10}$ DEMARCHI. Juliana. Leituras Complementares de Processo Civil. Organizador Fredie Didier Jr. Salvador: Editora Juspodivm, 2005, p.47.

"Art. 921 - É lícito ao autor cumular ao pedido possessório o de: I - condenação em perdas e danos; II - cominação de pena para caso de nova turbação ou esbulho; III - desfazimento de construção ou plantação feita em detrimento de sua posse.
} 
c) de cominação de multa - astreintes - que, por sua vez, integra um comando mandamental e, por fim,

d) de eventual demolição, a qual decorre de um comando de ordem executiva.

Neste diapasão, mencione-se a lição do jurista Humberto Theodoro Júnior ${ }^{12}$, a saber:

O procedimento especial dos artigos 920 usque 933 do Código de Processo Civil é, na verdade, unitário, por compreender, na mesma relação jurídica, tanto os atos de conhecimento como os de execução.

Deste modo, a sentença nas ações possessórias poderá contar com 04 (quatro) capítulos, sendo forte o tema na lição de Cândido Rangel Dinamarco:

Se peço reintegração de posse em cúmulo com indenização, o dispositivo da sentença que julgar o mérito deverá conter um preceito referente a cada um desses pedidos, ou seja, dois capítulos de sentença-um julgando a possessória e o outro, a indenizatória. Se peço 100 e a sentença me concede 80 , isso significa queo juiz acolheu minha pretensão a obter 80 e julgou improcedente a pretensão a obter os outros 20 (decompôs, portanto, um pedido que formalmente era uno). No primeiro caso já a demanda vinha colocada em capítulos (cúmulo de pedidos) e no segundo, não. Mesmo assim, uma singela operação mental de abstração conduz à claríssima percepção de que nos dois casos o julgado continha capítulos. Grifamos.

Vale salientar que a Teoria dos Capítulos da Sentença remonta de Giuseppe Chiovenda ${ }^{14}$ (fundador da Escola Italiana de Processo Civil), sendo que, no entendimento do mestre citado, os aludidos capítulos da sentença funcionariam tão-somente como unidades da decisão, diferenciando, neste patamar, a autonomia e a independência como elementos essenciais à conceituação daqueles.

\footnotetext{
${ }^{12}$ Op. Cit. p. 146

${ }^{13}$ DINAMARCO. Cândido Rangel. Capítulos da Sentença. 2. ed. São Paulo: Editora Malheiros. 2006. p. 10.

${ }^{14}$ CHIOVENDA. Giuseppe. L'azione nel sistema dei diritti. In Saggi di diritto processuali civile. I. Roma. Foro it. 1930.
} 
Também Enrico Túllio Liebman cuidou da matéria, alargando o discurso sobre o alcance dos capítulos da sentença para fins de incluir os pressupostos de admissibilidade do julgamento do mérito.

Por sua vez, Carnelutti restringiu os capítulos da sentença ao exame das questões (lembrando que foi Carnelutti quem definiu o que vem a ser uma "questão", conceituando-a como "um ponto controvertido" que se divide em duas faces: preliminares e prejudiciais de mérito - tema por demais interessante na área processual civil e que pode ser objeto de ponderações em outra oportunidade).

Outrossim e no entendimento de Cândido Rangel Dinamarco: ${ }^{15}$

$\{$...\} ao menos em face do direito brasileiro é inaceitável a posição de Carnelutti, que rejeita a divisão da sentença em capítulos referentes ao decisório, com a afirmação de que eles seriam exclusivamente o resultado da convivência da solução de duas ou mais questões, na motivação sentencial.

Assim e interpretando o posicionamento do mestre Chiovenda, o doutrinador Dinamarco ${ }^{16}$ esclarece que a sentença pode contar com capítulos que, necessariamente, devem sofrer o enquadramento devido no tocante à autonomia e independência de cada um, sendo "este o único meio de se identificar o alcance da fase recursal inerente à decisão eventualmente combatida. Em seu dizer e citando Chiovenda:

Disse Chiovenda, textualmente: "é também necessário, para aplicar a regra do art. 486, que os capitulos da sentença sejam autônomos e independentes, pois não se pode entender que aceite a sentença em relação ao capítulo dependente, ainda que não mencionado no ato de apelar, aquele que recorre da sentença no tocante ao capítulo principal." Invocou ainda o art. 543 do Código de seu tempo (substancialmente equivalente à do art. 336 do atual), portador da regra de que a reforma de um dos capitulos de sentença em grau de recurso deixa intactos os demais, a menos que sejam dependentes do

\footnotetext{
${ }^{15}$ Op. Cit. p. 19

${ }^{16}$ Op. Cit.p. 19
} 
capitulo formado (art. 543: “ se la sentenza sai cassata in alcuno dei capi, restano Fermi gli altri, salvo Che siano dipendenti dal capo in cui la sentenza fu cassata).

Nesta linha de pensamento, os capítulos da sentença sempre deveriam ser autônomos e independentes, posto que o recurso parcial importaria na aquiescência dos comandos não impugnados, o que geraria o trânsito em julgado destes.

\section{DO TRÂNSITO EM JULGADO DOS CAPÍTULOS NÃO RECORRIDOS - DA POSIÇÃO DO SUPERIOR TRIBUNAL DE JUSTIÇA(STJ)}

Consoante se vê, é possível extrair-se, de um único julgado, vários capítulos de decisão (capítulos de sentença), o que trouxe para o mundo jurídico a seguinte indagação: acaso o julgado contenha vários capítulos de sentença e tendo a parte, em seara recursal, se insurgido parcialmente contra o decisum (por exemplo, recorrendo apenas de um capítulo), estariam os demais capítulos acobertados pelo manto da coisa julgada, permitindo até mesmo uma possível liquidação antecipada destes?

Para Giuseppe Chiovenda a resposta é positiva, sendo firme o seu entendimento de que, não recorrendo a parte de determinado capítulo da sentença, ainda que de outros capítulos venha a interpor Recurso de Apelação, referido capítulo não recorrido restaria imutável, não permitindo mais qualquer modificação em seu contexto e hábil a conferir a parte o seu proveito.

De sorte que referido pensamento influencia diretamente no prazo para a eventual propositura da Ação Rescisória, cujo um dos pressupostos é exatamente o trânsito em julgado da decisão.

Segundo Dinamarco, na doutrina brasileira, o processualista Antônio Carlos de Araújo Cintra repudia a concepção de Chiovenda, demonstrando o seu apoio à lição de Liebman.

Por seu turno, José Afonso da Silva mostra-se bastante eclético no tocante ao tema, entendendo, inclusive, pela possibilidade do não-afastamento do recurso a nenhuma das teorias antecedentes.

Corroborando, Barbosa Moreira faz breve análise sobre o tema quando discorre sobre o recurso parcial e as limitações inerentes a este. 
Em recente decisão, o Superior Tribunal de Justiça ${ }^{17}$ asseverou a impossibilidade de ausência de trânsito em julgado de capítulo de sentença não recorrido, diante da também impossibilidade de cisão da coisa julgada material. Neste sentido:

PROCESSUAL CIVIL. AGRAVO REGIMENTAL. ACCÃO RESCISÓRIA. TERMO INICIAL DO PRAZO DECADENCIAL. IMPOSSIBILIDADE DE CINDIR A COISA JULGADA MATERIAL. TRANNSITO EM JULGADO QUE ACONTECE APENAS DEPOIS DA ÚLTIMA DECISÃO ACERCA DO ÚLTIMO RECURSO INTERPOSTO CONTRA O JULGADO RESCINDENDO. 1. As partes agravantes alegam que o capítulo da sentença referente à preliminar de litisconsórcio necessário transitou em julgado em 29.7.1996, uma vez que esta matéria não foi atacada pelos recursos cabíveis, e, por isso, consumou-se o prazo decadencial para a ação rescisória. 2. É pacífico o entendimento desta Corte Superior no sentido de que o prazo decadencial da ação rescisória deve ter como termo inicial o dia seguinte da data em que transitou em julgado o último recurso interposto contra sentença ou acórdão, seja ela parcial ou integral - em razão da impossibilidade de cindir a coisa julgada. Precedentes. 3. $O$ acórdão combatido pelo especial adotou posicionamento diverso da jurisprudência do Superior Tribunal de Justiça, na medida em que entendeu que houve trânsito em julgado da sentença na parte em que tratou da preliminar alusiva ao litisconsórcio passivo necessário, conquanto a referida decisão tenha sido atacada em outros capitulos, por outros fundamentos. 4. Agravos regimentais não providos. (AgRg no REsp 886.575/RJ, Rel. Ministro MAURO CAMPBELL MARQUES, SEGUNDA TURMA, julgado em 06/08/2009, DJe 19/08/2009). Grifamos.

\section{CONSIDERAÇÕES FINAIS}

Pelo breve relato, conclui-se que o tema afeto às ações possessórias instiga pela possibilidade de fungibilidade expressa

\footnotetext{
${ }^{17}$ Disponível em http://www.stj.gov/br/portal_stj/publicação/engine.wsp
} 
das tradicionais medidas que cuidam da questão, além do caráter dúplice que ostentam e da aceitação de vários comandos decisórios de ordem variada ao tempo da decisão da lide.

Assim, mister ressalvar que a fungibilidade das possessórias é pacificamente recebida (e permitida) também na esfera recursal, o que vai ao encontro da busca efetiva pela prestação jurisdicional de forma mais célere e eficiente.

Não se olvide de mencionar a característica de duplicidade afeta às ações possessórias, sendo que, neste particular, o bem da vida perseguido pelo autor poderá ser concomitantemente declarado como pertencente ao demandado, sendo que as figuras de demandante e demandado adotam posições similares dentro do mesmo feito.

Por fim, há que se aliar às referidas permissões alhures declinadas a franca hipótese de se conter o decisum vários capítulos, cada qual com a sua peculiaridade e contorno próprio situado no contexto da Teoria da Sentença.

Neste diapasão, é certo que a tese inerente à conduta da parte que não se insurgiu contra determinado capítulo da sentença, cujo resultado possa gerar o trânsito em julgado deste capítulo em específico (trânsito em julgado parcial do decisum), não encontrou respaldo junto aos tribunais superiores, sendo firme o posicionamento do Superior Tribunal de Justiça (STJ) neste sentido, o que deve ser observado pelos operadores do direito, salvo melhor juízo.

\section{REFERÊNCIAS BIBLIOGRÁFICAS}

ASSIS. Araken. Procedimento sumário. São Paulo: Editora Malheiros, 1996.

BRASIL. Código de Processo Civil. 42. ed. São Paulo: Editora Saraiva, 2010.

BRASIL. Superior Tribunal de Justiça. AgRg no REsp 886.575/RJ, Rel. Ministro Mauro Campbell Marques, Segunda Turma, julgado em 06/08/2009, DJe 19/08/2009. 
CHIOVENDA. Giuseppe. L'azione nel sistema dei diritti. In: Saggi di diritto processuali civile. I. Roma. Foro it. 1930.

DEMARCHI. Juliana. Leituras complementares de Processo Civil. Organizador Fredie Didier Jr. Salvador. Editora Juspodivm. 2005.

DINAMARCO, Cândido Rangel. Liebman e a cultura processual brasileira. In: Estudos em homenagem à Professora Ada Pellegrini Grinover. São Paulo: DPJ. 2005.

DINAMARCO. Cândido Rangel. Capítulos da sentença. 2. ed. São Paulo: Editora Malheiros, 2006.

MARINONI, Luiz Guilherme e ARENHART, Sérgio Cruz. Procedimentos especiais. São Paulo. Editora Revista dos Tribunais, 2008.

REZENDE, Astolfo. Manual de Código Civil (Paulo Lacerda), Ed. Jacinto Ribeiro, 1918, vol. VII, p. 4 apud Guido Arzua, Posse, o Direito e o Processo, $2^{\mathrm{a}}$. ed., Revista dos Tribunais, 1978, $\mathrm{n}^{\circ}$. I.

THEODORO JR., Humberto. Curso de Direito Processual Civil: Procedimentos Especiais. V. III. Rio de Janeiro: Editora Forense, 2008 . 